\title{
Seasonality of aerosol optical properties in the Arctic
}

Lauren Schmeisser ${ }^{1,3^{*}}$, John Backman ${ }^{2}$, John A. Ogren ${ }^{1,3}$, Elisabeth Andrews ${ }^{1}$, Eija Asmi ${ }^{2}$, Sandra Starkweather ${ }^{1,3}$, Taneil Uttal ${ }^{3}$, Markus Fiebig ${ }^{4}$, Sangeeta Sharma ${ }^{5}$, Kostas Eleftheriadis ${ }^{6}$, Stergios Vratolis ${ }^{6}$, Michael Bergin ${ }^{7}$, Peter Tunved ${ }^{8}$, Anne Jefferson ${ }^{1}$

${ }^{1}$ University of Colorado, Cooperative Institute for Research in Environmental Sciences, Boulder, CO, USA

${ }^{2}$ Finnish Meteorological Institute, Atmospheric Composition Research, Helsinki, Finland

${ }^{3}$ National Oceanic and Atmospheric Administration, Earth System Research Laboratory, Boulder, CO, USA

${ }^{4}$ Norwegian Institute for Air Research, Kjeller, Norway

${ }^{5}$ Environment and Climate Change Canada, Science \& Technology Branch, Climate Research Division, Toronto,

Canada

${ }^{6}$ Institute of Nuclear and Radiological Science \& Technology, Energy \& Safety, Environmental Radioactivity Laboratory, NCSR Demokritos, Athens, Greece

${ }^{7}$ Duke University, Department of Civil \& Environmental Engineering, Durham, NC, USA

${ }^{8}$ Stockholm University, Department of Environmental Science and Analytical Chemistry, Stockholm, Sweden

*Now at University of Washington, Department of Atmospheric Sciences, Seattle, WA, USA

Correspondence to: Lauren Schmeisser (lauren.schmeisser@gmail.com)

\section{Supplemental Materials}
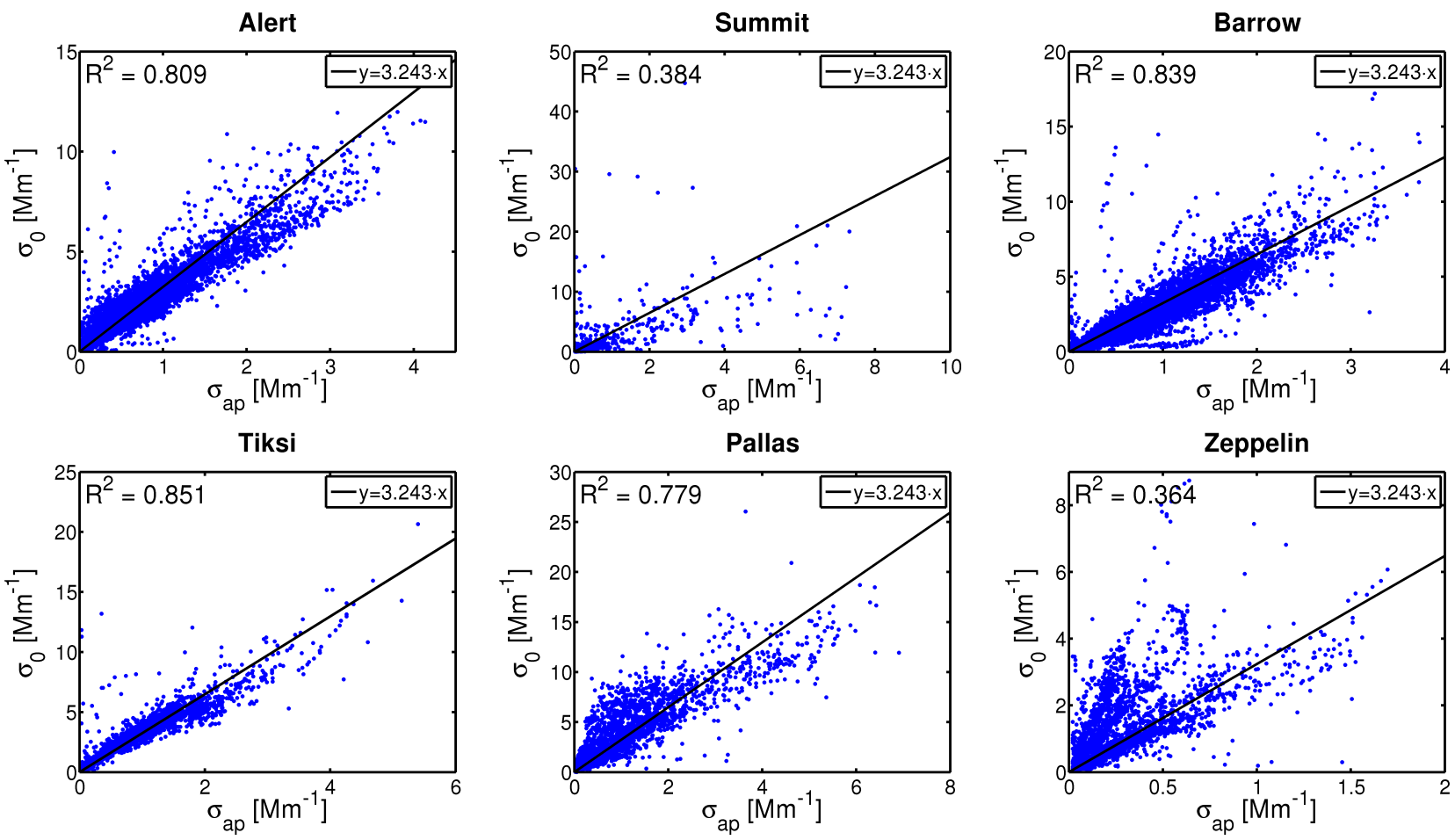

Figure S1. Scatter plots comparing Aethalometer and reference absorption data, $\sigma_{0}$ and $\sigma_{a p}$, respectively, for each of the six Arctic monitoring stations. Regression coefficients are noted in the top left of each plot. A reference line of $\mathrm{y}=3.243 \mathrm{x}$ is shown in black on each plot. 